\title{
Discussion of different Remote sensing satellite possibilities for scientifical Earth observations.
}

\author{
Aybek Arifjanov ${ }^{1}$, Shamshodbek Akmalov ${ }^{* 0000-0002-5302-7851]}$, Shakhzod Shodiev ${ }^{1}$, and \\ Abdukarim Haitov ${ }^{1}$
}

Tashkent Institute of Irrigation and Agricultural Mechanization Engineers, Tashkent, Uzbekistan

\begin{abstract}
More than 1,000 satellites are launched into space, and they differ in their functions, rotation orbits, resolution, and other properties. Scientists divide the satellites into low-resolution, mediumresolution, high-resolution, and very high-resolution satellites by their properties. Now, the biggest challenge facing scientists is to use some of these different resolution images in their field. To get the expected result, it is very important to analyze the image that needs an which gives more accurate results. Therefore, the main attention of this article is aimed to find the answer to these problems. In this article 3 satellite images which have different resolution are analyzed. The possibility of middle-resolution images of MODIS, high-resolution images of Landsat, and very high-resolution images of WorldView-2 (WV-2) satellites using GIS are analyzed. A research area was the Syrdarya region, and downloaded different images of satellites of this area and compared with using e Cognition. According to the results, a more accurate satellite image for irrigation sets information is WorldView-2 images. In comparison analysis, it shows more accurate properties than other satellite images. As irrigation sets are small objects for the analysis, very high spatial resolution satellite images are important. Water discharge and surface change happen very fast; thus, it requires daily monitoring of the condition. And in this case, the temporal resolution of the MODIS and Landsat is 16 day, and it is a too long period.
\end{abstract}

\section{Introduction}

During the last 20 years, satellites were launched into the sky. Those satellites were sending information about the Earth with different possibilities and properties. The main problem of the branches now is to find satellite information that gives more accurate results in analysis and financially accessible. Moreover, during the literature

\footnotetext{
"Corresponding author: shamshodbekjon@mail.ru
} 
review, we have discovered the following benefits of using each satellite. The benefits of using MODIS images [5]:

$>$ MODIS Terra scanner has NDVI layers, which save time in calculations and increase the accuracy of them;

$>$ MODIS Terra scanner is the only satellite that has been importing images to Earth incessantly since 2000. Other existing satellites sometimes deviated from the schedule due to technical disrepairs and other reasons, and other satellites have been launched just in recent years. The other remaining satellites have low resolution images. Change of vegetation layer occurs in a short period, and its data should be collected incessantly, and MODIS is a perfect satellite for it [28];

$>$ Images of MODIS have been used widely by the scientists of Uzbekistan;

$>$ MODIS images are easily accessible;

$>$ MODIS takes large scale images that cover wide areas $(250 \mathrm{~m} / \mathrm{pixel})$, and it allows making analyses on large scales;

$>$ Agricultural fields are large, and the low resolution of MODIS helps to merge them into 1 or several pixels. As a result, 1 pixel includes NDVI information on one type of vegetation field approximately; thus, the work will be simplified [7].

Advantage of using Landsat long term images:

$>$ Landsat satellites have been supplying scientists with images since 1970. Data collected from the 70 s onwards give us a chance to analyse the land cover changes that have occurred in the study area during a long period [25];

$>$ Landsat 8 satellite was launched in 2013, and it is a new data source for RS specialists [9];

$>$ It is the first-ever satellite with high resolution and multi bands, and it eases LC analysis;

$>$ These images are easily accessible;

> Satellite sensors resolution is higher in comparison with other free satellite images.

Advantage of using WV-2 satellite data for water objects and irrigation sets extraction analysis:

$>$ WV2 is a very high resolution satellite image, and it is possible to see even the smallest water sets (with $5 \mathrm{~m}$ width). The size of the panchromatic band is $0.5 \mathrm{~m}$, and it gives the possibility to analyse very small objects $(>0.5 \mathrm{~m})[13]$;

$>$ Those images have shown very good results for the classification of small objects as buildings, water sets and agricultural fields $[1,11,12]$;

> Its hyperspectral satellite, multi MS1, MS2, and PAN bands increase the classification possibilities during analysis;

$>$ With the help of WV2 image layers, about 40 indexes were created, and more than 10 of them are NDWI indexes [18].

The advantages of WV2 bands for land classification and especially for water object classifications (to analyse their width, length, blur, depth, and determining the amount of sediment in it) are given in detail on the website digitalglobe.com and in the articles of Tarantino [26], Pueto et al. [22], Elshaarawy et al. [11]. New bands of WV2 satellite (especially Coastal and NIR2) are now widely used in water objects extraction.

In addition, it is possible to create different indexes using these satellite image layers. In different years by different scientists, different indexes for analysing land and water objects were created [12, 19, 20, 21, 27]. Those indexes increase the accuracy of the results [16]. The possibility of using these indexes for Landsat image analyses is one of the advantages of the Landsat images using. In the Landsat and WV-2 image 
analysis, some of these indexes will be used. David de la Fuente created 34 indexes using WV-2 data [10].

WV-2 data was used by Leonhard and Ferrè [15] for extracting water objects; B. M. G. Ribeiro [23], Chen et al. [8], Rizvi and Mohan [24], Kokje and Gao [14], Khin et al. [13] and other scientists used it to create land cover maps, Naif Muidh Alsubaie [1] for bathymetry, Khin [13] for urban drainage system modeling. Nouri et al. created the NDVI index using WV 2 images [18]. Scientific research using WV-2 images gave positive results. Indeed, WV-2 is a hyperspectral satellite; these properties make it very useful to observe the processes and changes on land cover in the water sector and the environment [16].

Field data experiments were used as very important data for validation of all image results. Besides the advantages of using all this data, it also has some limits. Knowing and taking into account these limits helps us to organise analysis correctly.

As MODIS images are of low resolution, it is impossible to use them for high accuracy analysis. It influences its accuracy (Figure 1).

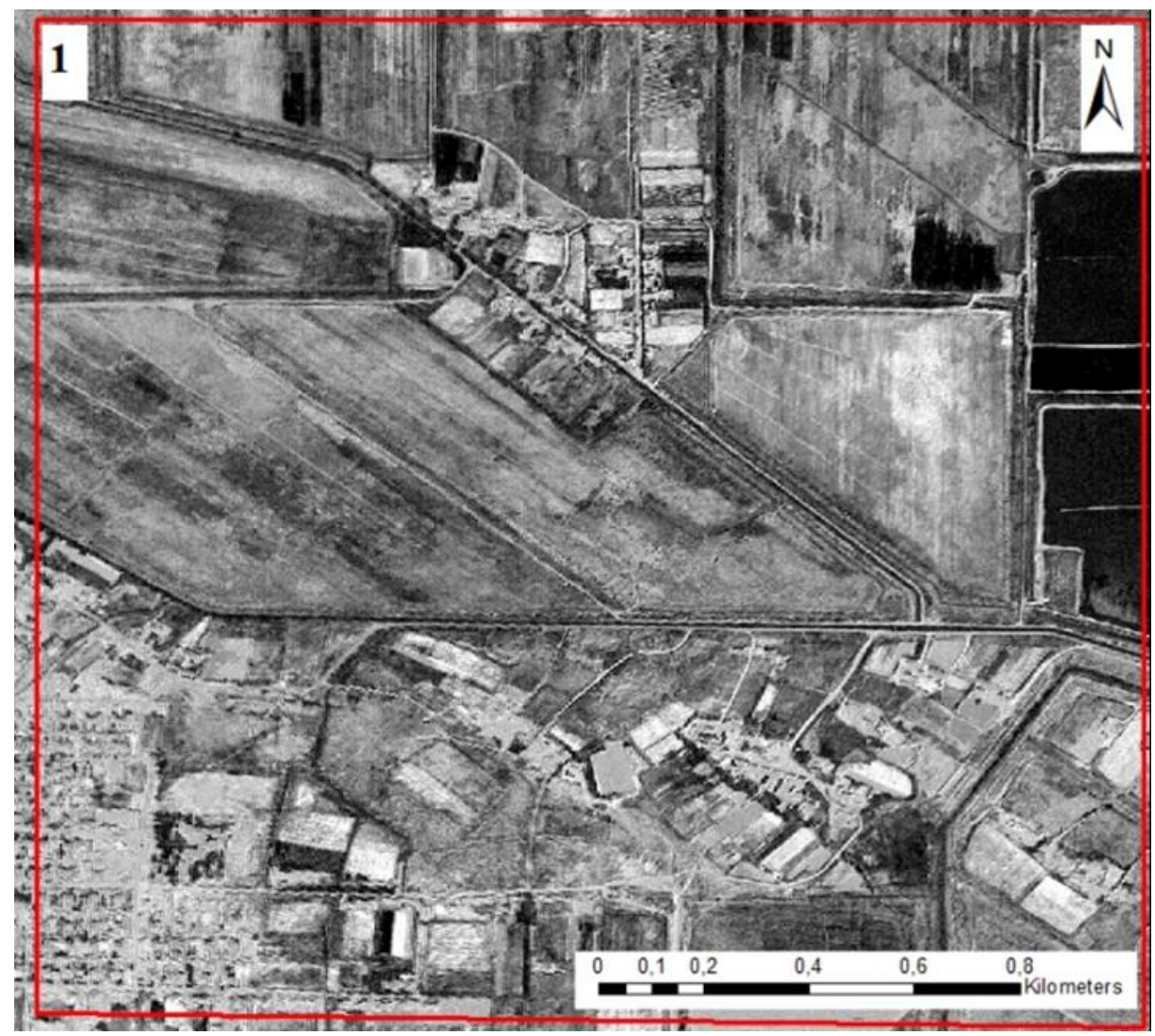



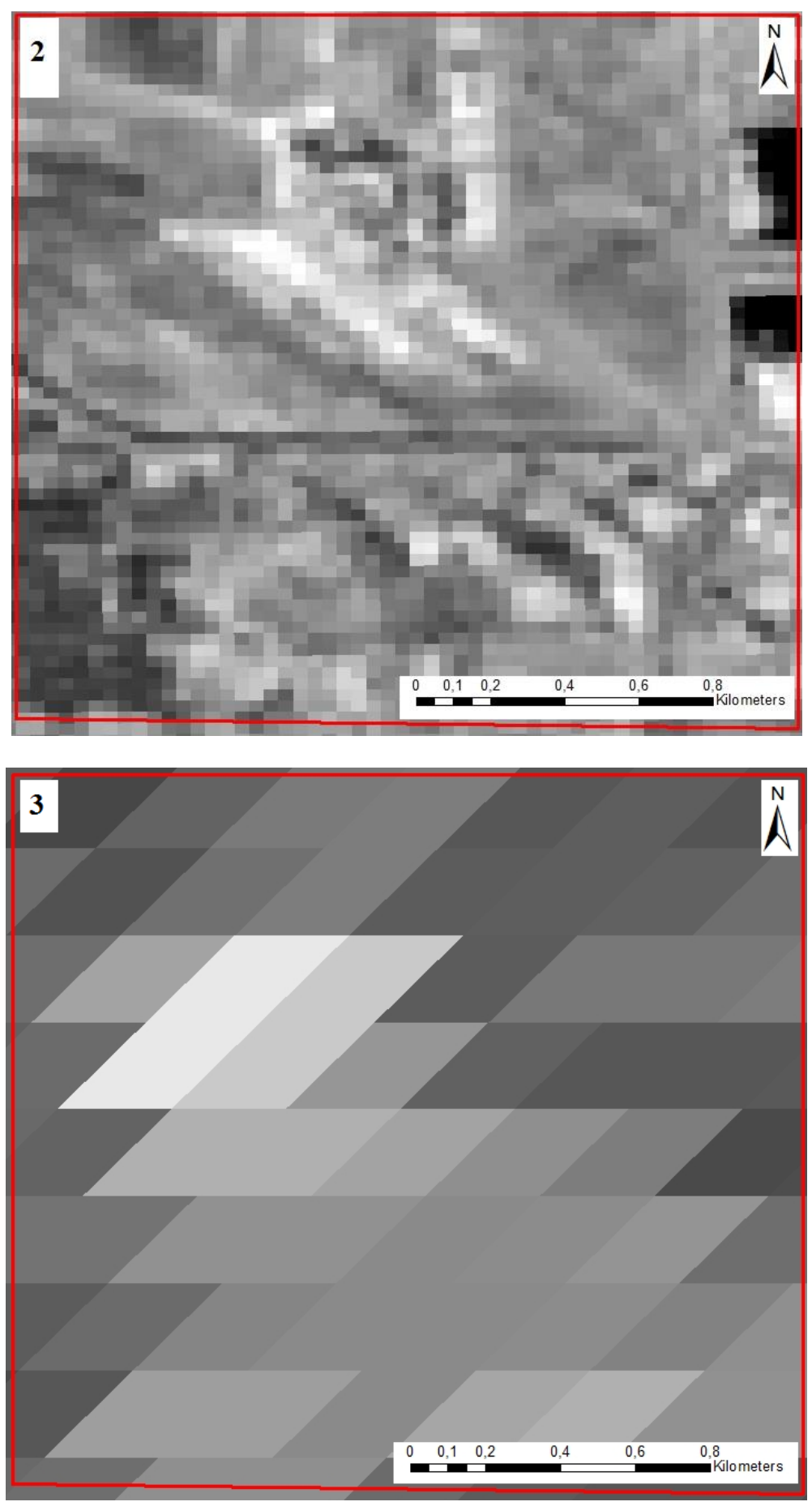

Fig. 1. Spatial resolution of different satellite images ( 1 is WorldView2 satellite image NDVI value (12.09.2012); 2 is Landsat OLI TIRS satellite image NDVI value (10.09.2013); 3 is MODIS TERRA satellite image NDVI value (13.09.2012)) 
For this reason, it is not usable for detailed classification of the land surface, water lines, urban areas and other classifications which require high quality.

Landsat Long term data is the most suitable dataset for long time land surface change. But it also has some limits. Because of some technical problems, sometimes Landsat satellites did not send information. And clouds also highly affects their images. That is why more images are not usable, and the classification of objects smaller than 30 $\mathrm{m}$ shows few results in these images [6].

WV2 images are very important and provide many relevant data for all image analysis. VHR of these images can increase the quality and possibilities of all analysis. But usage of these images globally has not developed because of their costs. Square of satellite image capturing is very little for global analysis. To do a global analysis, we need $100 \mathrm{~s}$ of this image. That is why scientists use this data more often for correlation or creating general methods. That is why it has not been used for regional and global analysis.

A basic issue of RS imagery starts with the appearance of VHR imagery and flying high resolution satellites to space. The problem was to analyse them with high accuracy. By this period, middle and low resolution images were analysed with the PBIA method. This analysis was realized according to the DN value of every pixel.

The high cost of RS images is another problem.

The analysis problem consists of joining the outer objects without data to segment objects in MODIS imagery analysis. Because of this problem, we have to segment images into pixel levels. After this, we can reach the classification of data objects into separate groups. The results show that it is impossible to segment them in the highest SP because we do not have separate data of the areas beforehand.

Another issue concerning MODIS images in OBIA analysis is creating homogeny objects. Because spatial resolution of MODIS images are very low and do not save its accuracy. Furthermore, there is no possibility of visual observations in homogeny segmentation.

There appeared some difficulties in realizing the OBIA visual classification of Landsat 1 and 3 satellite images. The first reason for this is the poor spatial resolution ( $80 \mathrm{~m}$ pixel). The second reason is fewer layers of bands; those images consist of only NIR, Green and Red bands. The existing two NIR bands give the opportunity to increase the accuracy of images and create the indexes in different ways (NDVI, NDWI...). But the absence of a Blue band destroys the opportunity of identifying the visual appearance of images. Because Blue, Green and Red bands combination gives us visual appearance. Furthermore, poor resolution of images brings difficulties in identifying the borders of objects and evaluating segment results. It is better to use indexes in Landsat 1-3 images analysis [2,3,4].

By the Landsat 1 and 3 satellites, it was impossible to classify artificial area. The reason for this is the low spatial and spectral resolution. However, in separating artificial areas in Landsat 5-7-8, we faced a lot of other problems. This was the building of roofs in the Sirdarya region, consisting of mud, cement, and slate. These roofs ' DN value in different bands is absolutely similar to the spectral indicators of cultivated mineral and salinize soil. The DN indicators are similar to all spectral diapason. For this reason, in most cases, it is observed that "Open grount" was classified as "Artificial area" and vice versa.

If this happened in PBIA, it would be impossible to escape because of the same pixel values of different objects. But, in OBIA, it is possible to separate them and implement them in various procedures. The algorithm of "Select samples" in the panel 
of classification will help it. With the help of this algorithm, it is possible to classify them separately and analyse them by the method of "Sample information".

The most common issue in the classification of VHR images to OBIA is separately segmenting water and aquatic vegetation. Their DN is very similar, and the location of water plants in water brings some difficulties in segmentation. Therefore, segmentation parameters are evaluated close to the minimum. It is impossible to segment small canals from water plants. For this reason, the smallest water objects usually join the vegetation area during the classification [4].

The second problem is the classification of asphalt roads and water objects because of their similar DN value. The feeding canals from rivers and their mud consistence is the reason for this. It damages the accuracy of results.

\section{Materials and Methods}

Remote sensing consists of four resolutions, and satellite images differ according to these resolutions [17]:

- spatial,

- spectral,

- radiometric,

- temporal.

We evaluated images according to those four elements using different satellite data. We discussed the pros and cons. It is very important to choose the proper one from those resolutions to increase the quality and speed of analysis.

Spatial resolution. The wrap ability of a land surface to one pixel of satellite sensors is called spatial resolution. In some cases, the spatial resolution depends on the orbit where it is flying.

Nowadays, much attention is paid to increasing the spatial resolution of satellite sensors. Because improving the spatial resolutions will increase the quality of images. Here are given examples about our used satellite sensors` resolutions (Table 1) [17]:

Table 1. Spatial resolution of used satellites

\begin{tabular}{|c|c|}
\hline Satellite & Spatial Resolution \\
\hline MODIS & $250 \mathrm{~m}$ \\
\hline Landsat & Multispector $30 \mathrm{~m}$, Panchromatic $15 \mathrm{~m}$ \\
\hline WorldView2 & Multispector $2 \mathrm{~m}$, Panchromatic $0.5 \mathrm{~m}$ \\
\hline
\end{tabular}

As the spatial resolution of satellites develops, the quality of images is better (Navulur, 2006). It is obvious from the images that the smallest part of the image contains pixels, the higher the quality of the image, it allows learning it in details (Fig. $1)$.

If we look at Figure 1, all were taken from one territory but different satellites. On the first image, WV2 NDVI spatial resolution is $2 \mathrm{~m}$; we can see water objects, different plants, settlements and even decorative gardens. The second image is Landsat NDVI; its spatial resolution is $30 \mathrm{~m}$. Here we can see objects that are higher than 30 meters, large fields, pools but here; we cannot observe settlements and small water branches. The third image is MODIS NDVI; its spatial resolution consists of $250 \mathrm{~m}$. Here we can see only differences of pixels, nothing else. 
However, we should keep in mind that improving satellites' spatial resolution may decrease in their trapeze size (Figure 2).

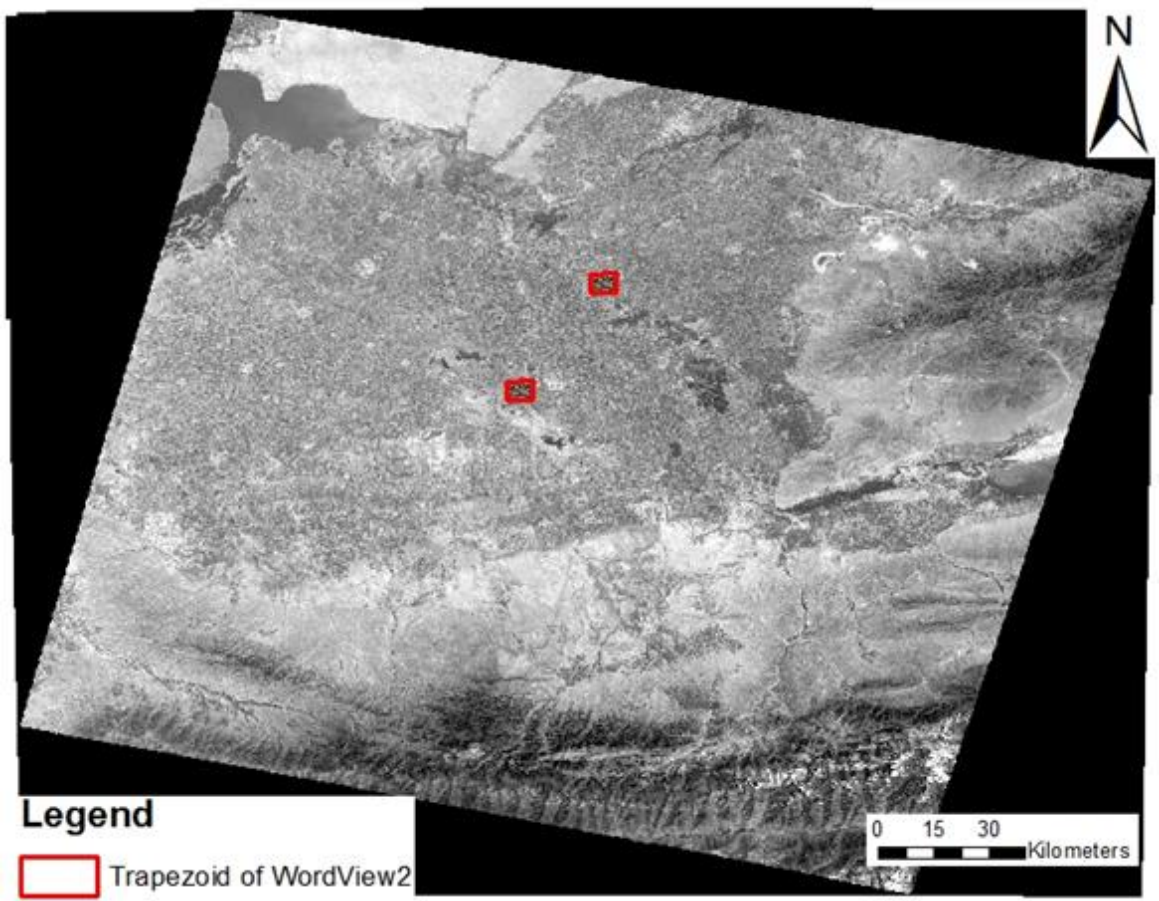

Fig. 2. Difference trapeze of image camera of Landsat and WV2 scanner.

The above mentioned in Fig. 2 is demonstrated WV2 image shooting trapeze and Landsat trapeze. Thus, we need several hundreds of trapeze images from the WV2 satellite for Landsat trapeze area research for our analysis. So, one MODIS scanner trapeze equals the sum of hundreds of Landsat trapezes.

For this reason, no matter how good WV2 satellite images spatial resolutions are, it is not possible to do RS analysis for large areas. Because one needs to buy a lot of trapeze images, so it may bring big financial expenses for practical investigations. Researchers usually buy WV2 images of a small territory to prevent this problem and use them for other lower resolution images analysis validation.

According to spatial resolution, WV2 satellite sensor opportunities are found as the clearest. But their small trapeze and high cost restrict its wide usage. For this reason, it is better to use WV2 satellite images in validation, and it is recommended to implement other cheap satellite images. However, their capture is a little smaller in comparison to the first one.

The spectral resolution is a feature of the sensor that takes images in different wavelengths of the specter. Nowadays, scientists use multi-spectral, super spectral and hyperspectral sensor satellite images in modern remote sensing based on this feature. As we know, different objects reflect rays differently in different wavelengths. Therefore, to determine any feature of an object, it is necessary to learn its different ray -reflecting feature in different specter lengths. For example, to use an image as a backdrop in GIS, it is enough to have its image taken in specter 3 bands: Green, Blue, and Red (RGB). 
But, if we want to obtain more data from it, for example, to express impervious surfaces, vegetation classification and other dates, we should use the near infrared band (NIR) as well as the above-mentioned bands [17].

In this case, MODIS scanners' opportunities are not restricted. It takes images in 36 spectra in $0.4 \mu \mathrm{m}$ to $14.4 \mu \mathrm{m}$ wavelengths and transfers them to Earth. As mentioned above, the more bands, the easier it is to identify an object. In this regard, Landsat 8 satellite scanner takes second place. Its spectral image shoots in 10 bands (coastal, blue, green, red, NIR, SWIR1, SWIR2, Pan, TIR1, TIR2). If we account Cirus identifier of water atoms as one band, Landsat 8 OLI TIRS band numbers will reach 11 bands totally. The issue is that the Cirus band does not take images in light wavelength diapason, but it works according to the light return function of flaying aerosols.

The last place is given to the WV2 satellite. These satellite sensors send us images in 9 spectral wavelengths. These bands are Coastal, Blue, Green, Yellow, Red, RedEdge, NIR1, NIR2 and Pan.

Regarding this, MODIS satellite scanners are highly evaluated. But because of its poor spatial resolution, it is not widely used. In our case, MODIS is recommended to implement for analyzing large territories.

Radiometric resolution refers to the number of divisions of bit depth (for example, 255 for 8-bit, 65,536 for 16-bit, and so on) in data collected by a sensor (support.esri.com). The radiometric resolution specifies how well the differences in brightness in an image can be perceived; this is measured through the number of grey value levels. The maximum number of values is defined by the number of bits (binary numbers). An 8-bit representation has 256 grey values, a 16 bit (ERS satellites) representation 65.536 grey values [29].

The advantage of a higher radiometric resolution is rather small - when comparing LANDSAT-MSS (6 bits) and TM (8 bits), the improvement is in the order of 2-3\% [6].

As much raises the radiometric resolution, so big is the difference between black and white levels. Radiometric resolution of used sensors are the following (Table 2):

Table 2. Radiometric resolution of used sensors

\begin{tabular}{|c|c|}
\hline Satellite & Radiometric resolution (bits) \\
\hline MODIS & 12 \\
\hline Landsat & 8 \\
\hline WV2 & 11 \\
\hline
\end{tabular}

Though MODIS has the highest radiometry, it is less used. This is even though its resolution is clear, one pixel captures of $250 \mathrm{~m}$ area. So, separate images of objects are not available. In this case, WV2 satellite images are recommended. Because primarily it shows the borders of the objects clearly and its volume is a little bit less than MODIS'.

In addition to spatial, spectral, and radiometric resolution, the concept of temporal resolution is also important to consider in a remote sensing system. Thus, the actual temporal resolution of a sensor depends on various factors, including the satellite/sensor capabilities, the swath overlap, and latitude [30].

The ability to collect imagery of the same area of the Earth's surface at different periods is one of the most important elements for applying remote sensing data. Spectral characteristics of features may change over time, and these changes can be detected by collecting and comparing multi-temporal imagery. The time factor in imaging is important when [30]:

- persistent clouds offer limited clear views of the Earth's surface (often in the tropics) 
- short-lived phenomena (floods, oil slicks, etc.) need to be imaged

- multi-temporal comparisons are required (e.g. the spread of a forest disease from one year to the next)

- the changing appearance of a feature over time can be used to distinguish it from near-similar features (wheat/maize).

So this resolution is marked by the number of days of the satellite's return. This helps to thoroughly research different processes in nature and ecological changes. Regarding this, the satellites are evaluated as follows (Table 3).

Table 3. The temporal resolution of used sensors

\begin{tabular}{|c|c|}
\hline Satellite & Temporal resolution (days) \\
\hline MODIS & 16 \\
\hline Landsat & 16 \\
\hline WV2 & 1 \\
\hline
\end{tabular}

\section{Results and Discussion}

The opportunities of the WV2 satellite are greater than those of the rest of the satellites for water extractions. Irrigation systems are small objects with small size; for this reason, it is important to choose images taken with very high spatial resolution sensors (in this case, WV-2 answers all the requirements. Spatial resolution of MODIS is 250$1000 \mathrm{~m} / \mathrm{pixel}$, Landsat $15-30 \mathrm{~m} / \mathrm{pixel}$, Worldview-2 is $0,5-5 \mathrm{~m} /$ pixel. With the spectral properties, WV-2 is the best satellite image; it has new spectral diapasons as yellow and others, which gives the possibility to analyze water objects with high accuracy. With other properties, WV-2 show its advantage.

\section{Conclusions}

According to the results, it can be recommended WV-2 to small objects classification. Multiband of satellites gives the possibility to create different indexes. But about bands, MODIS is more usable; it has 36 bands. But its spatial resolution is very low.

\section{References}

1. Alsubaie N.M. The Potential of Using Worldview-2 Imagery for Shallow Water Depth Mapping. Diss. University of Calgary, 2012. http://theses.ucalgary.ca/handle/11023/353 (accessed 10.07.2019). (2012).

2. Arifjanov A., M. Otaxonov, L. Samiev, Sh. Akmalov. Hydraulic calculation of horizontal open drainages. E3S Web of Conferences 97, 05039 (2019). FORM2019 (a) (2019)

3. Arifjanov A., Sh. Akmalov, I. Akhmedov, D. Atakulov, Evaluation of deformation procedure in waterbed of rivers. XII International Scientific Conference on Agricultural Machinery Industry. IOP Conf. Series: Earth and Environmental Science 403 (2019) 012155 (b). (2019)

4. Arifjanov A., L. Samiev, T. Apakhodjaeva, Sh. Akmalov. Distribution of river sediment in channels. XII International Scientific Conference on Agricultural Machinery Industry. IOP Conf. Series: Earth and Environmental Science 403 (2019) 012153 (c).(2019) 
5. Arifjanov A., T. Apakhodjaeva, Sh. Akmalov. Calculation of losses for transpiration in water reservoirs with using new computer technologies. International Conference on Information Science and Communication Technologies (ICISCT). IEEE (2019) Pp 1-4 (d). (2019)

6. Arifjanov A., S. Akmalov, T. Apakhodjaeva, D. Tojikhodjaeva.. Comparison of pixel to pixel and object-based image analysis with using WorldView-2 satellite images of Yangiobod village of Syrdarya province. Inter Carto Inter GIS. https://doi.org/10.35595/2414-9179-2020-2-26-313-321. (2020)

7. Arifjanov A.M., S.B Akmalov, L.N.Samiev.. Extraction of urban construction development with using Landsat satellite images and geoinformation systems. Journal of Water and Land Development. No. 48 (I-III) p. 65-69. DOI 10.24425/jwld.2021.136147. (2021).

8. Chen Z., Ning N., Zhang J. Urban Land Cover Classification Based on WorldView-2 Image Data. In Geomatics for Integrated Water Resources Management (GIWRM), International Symposium on. IEEE. 2012. pp. 1-5. (2012).

9. Dao P.D., Liou Y. Object-Based Flood Mapping and Affected Rice Field Estimation with Landsat 8 OLI and MODIS Data. Remote Sensing,. 7. (5). pp. 5077-97. (2015)

10. de la Fuente D., Suarez J., Yague J, Pedrazzani D. Potentiality of World-View 2 Data for Precision Agriculture. In Geoscience and Remote Sensing Symposium (IGARSS), IEEE International. pp. 2825-28.(2013)

11. Elsharkawy A., Elhabiby M., El-Sheimy N. Improvement in the Detection of Land Cover Classes Using the WorldView-2 Imagery. In. ASPRS. International Scientific Conference 2012. pp. 19-23.(2012).

12. Jawak, S. D., Luis A.J. A. Rapid Extraction of Water Body Features from Antarctic Coastal Oasis Using Very High-Resolution Satellite Remote Sensing Data. Aquatic Procedia,. 4. pp. 125-32. (2015)

13. Khin M.L., Shaker A., Joksimovic D., and Yan W.Y. The Use of WorldView-2 Satellite Imagery to Model Urban Drainage System with Low Impact Development (LID) Techniques. Geocarto International,.31. (1), pp. 92-108.(2016).

14. Kokje, A.A., Gao J. A. Simplified Approach for Classifying Urban Land Cover Using Data Fusion. In Proceedings of the SIRC NZ Conference,. https://otago.ourarchive.ac.nz/handle/10523/4240 (accessed 10.07.2019).(2013)

15. Leonhard, G., Ferrè N. Master in Space Applications for Early Warning and Response to Emergencies Final Report. Accessed June 8,. http://aulavirtual.ig.conae.gov.ar/moodle/pluginfile.php/513/mod_page/content/75/ Final\%20report_Leonhard.pdf. (accessed 10.07.2019).(2015).

16. Maglione P., Parente C., Vallario A. Coastline Extraction Using High Resolution WorldView-2 Satellite Imagery. European Journal of Remote Sensing, 47, pp.68599.(2014).

17. Navulur, K. Multispectral Image Analysis Using the Object-Oriented Paradigm. CRC Press. (2006).

18. Nouri, H., S. Beecham, Sh. Anderson, Nagler. P. High Spatial Resolution WorldView-2 Imagery for Mapping NDVI and Its Relationship to Temporal Urban Landscape Evapotranspiration Factors. Remote Sensing, 6. (1). pp. 580-602. (2014)

19. Pengra B, Long J., Dahal D., Stehman S.V., Loveland T.R. A Global Reference Database from Very High Resolution Commercial Satellite Data and Methodology 
for Application to Landsat Derived 30m Continuous Field Tree Cover Data. Remote Sensing of Environment,165. pp. 234-248.(2015).

20. Platt R.V. Wildfire Hazard in the Home Ignition Zone, An Object-Oriented Analysis Integrating LiDAR and VHR Satellite Imagery. Applied Geography, 51. pp. 108-17. (2014).

21. Platt R.V. Wildfire Hazard in the Home Ignition Zone, An Object-Oriented Analysis Integrating LiDAR and VHR Satellite Imagery. Applied Geography,51. pp 108-17.(2014).

22. Puetz, A.M., Lee K., Olsen K. WorldView-2 Data Simulation and Analysis Results. In Algorithms and Technologies for Multispectral, Hyperspectral, and Ultraspectral Imagery XV, International Society for Optics and Photonics,pp. 73340U. (2009).

23. Ribeiro, B. M. G., and L. M. G. Fonseca. Evaluation of WorldView-2 Imagery for Urban Land Cover Mapping Using the InterIMAGE System. In Proceedings of the 4th Conference on Geographic Object-Based Image Analysis GEOBIA, Rio de Janeiro, Brasil,. pp. 206-210.(2012).

24. Rizvi, I.A., and B. K. Mohan. Object-Based Analysis of WorldView-2 Imagery of Urban Areas. In Geoscience and Remote Sensing Symposium (IGARSS). IEEE International.. pp 431-434 (2012).

25. Song, C., C.E. Woodcock, K.C. Seto, M.P. Lenney, and S.A. Macomber. Classification and Change Detection Using Landsat TM Data, When and How to Correct Atmospheric Effects? Remote Sensing of Environment. V. 75. (2). pp. 230-234, (2001).

26. Tarantino, C., F. Lovergine, G. Pasquariello, M. Adamo, P. Blonda, and V. Tomaselli. 8-Band Image Data Processing of the Worldview-2 Satellite in a Wide Area of Applications. Earth Observation.. pp. 137-152.(2012)

27. Wolf, A.F. Using Worldview-2 Vis-NIR Multispectral Imagery to Support Land Mapping and Feature Extraction Using Normalized Difference Index Ratios. In Algorithms and Technologies for Multispectral, Hyperspectral, and Ultraspectral Imagery XVIII. 2012. (8390). Pp. 83900.(2012).

28. glovis.usgs.gov. Last acces 02.01.2020

29. www.seos-project.eu. Last acces: 02.01.2020

30. www.nrcan.gc.ca. Last acces: 02.01.2020 